accurately determined by means of the thermometer. Within the last few years very great attention has been given to the indications furnished in many diseases by this little instrument, but in no other disease have the investigations been so numerous as in the one under consideration, and the results obtained amply repay the trouble. In typhoid fever the thermometer is indispensable. You see in the wards how much importance I attach to the charts at the bedside of the patients. On these charts are records of the patients' temperature, taken by the house-surgeon twice at least daily, at 8 A.m. and 6 r.M., and marked by a black line on the chart. The frequency of the pulse is also recorded at the same time by a red line. We have likewise tabulated the number of the evacuations in the preceding twenty-four hours, whether loose or formed, and, if containing blood, its quantity. These charts represent very true pictures of the progress of the case, and by looking at them $\bar{I}$ can most generally tell, before $I$ ask either the patient or the nurses any questions, whether that progress is favourable or otherwise. From the information the thermometer gives me I can fully endorse the following statement:-

"The physician who judges of fever cases without a knowledge of the facts of thermometry, and without taking note of the temperature, is like a blind man trying to find his way. With much practice and great intelligence, the blind man may succeed; but he will more frequently fail, and always do, only with great diffeulty and unsatisfactorily, what to him who sees requires no effort."

Let me now show you how far this is true. During the first four or five days the general symptoms which may then, as I have told you, accompany the disease-viz., the rigor, the languor and feebleness, headache, epistaxis, giddiness, pain in the back and aching of the limbs, the appearance of the tongue, the state of the bowels, the condition of the urine, \&c., - may not be very distinct, or any one of these morbid symptoms may be entirely absent. In a considerable number of cases, in fact, it would be impossible for you to say, without using the thermometer, whether the patient were suffering from typhoid fever or not. But the thermometris course of the disease at this time, unless it supervenes on some other malady, is very regular; and by taking the temperature at 8 A.M. and 6 P.M. for three days the presence of typhoid fever may be decided. On the other hand, one single observation may, with very great probability, negative the existence of the disease.

The following is the formula (from Wunderlich) of this initial stage :-

\begin{tabular}{llllllll} 
& \multicolumn{9}{c}{ Morning. } & & \multicolumn{1}{c}{ Evening. } \\
1st day & $\ldots$ & $\ldots$ & $98 \cdot 6^{\circ} \mathrm{F}$. & $\ldots$ & $\ldots$ & $100 \cdot 4^{\circ} \mathrm{F}$. \\
2nd & $\ldots$ & $\ldots$ & $\ldots$ & $99 \cdot 4^{\circ}$ & $\ldots$ & $\ldots$ & $101 \cdot 4^{\circ}$ \\
3rd & $\ldots$ & $\ldots$ & $\ldots$ & $100 \cdot 4^{\circ}$ & $\ldots$ & $\ldots$ & $102 \cdot 6^{\circ}$ \\
4th &, & $\ldots$ & $\ldots$ & $101 \cdot 6^{\circ}$ & $\ldots$ & $\ldots$ & $101^{\circ}$
\end{tabular}

If, then, a person, previously quite well, feels uneasy, perhaps has a rigor, and in the evening we find his temperature about $100^{\circ} 4^{\circ}$ or $101^{\circ} \mathrm{F}$., falling the next morning about a degree, rising again in the evening, and approximately following the above course, the disease may be diagnosed with tolerable certainty.

On the other hand, the disease is not typhoid fever if (1) on the second, third, or fourth evening the temperature approximates even to the normal $\left(98 \cdot 6^{\circ} \mathrm{F}\right.$.); (2) if during the first two days the temperature rises to $104^{\circ} \mathrm{F}$.; (3) if between the fourth and sixth days the evening temperature of a person under middle age does not reach $103^{\circ}$; (4) if the temperature on two of the first three evenings is the same; or (5) if it is the same on the second and third mornings. From the fourth to the tenth day the evening temperatures are tolerably uniform, the highest being most generally on the evenings of the fourth, fifth, or sixth days, and reaching from $104^{\circ}$ to $105.5^{\circ} \mathbf{F}$., or even bigher. The morning temperatures are from $1^{\circ}$ to $26^{\circ} \mathrm{F}$. lower than the evening ones; on the fifth, sixth, and seventh days the variations between the morning and evening temperatures being less than take place from the sixth or seventh to the ninth or tenth days. During this period (from the fourth to the tenth or twelfth day), if the general symptoms are obscure, an absolute diagnosis may not be readily made, and the disease may be confounded with several others, unless thermometric observations estend over several days. Here, again, the thermometer gives us then very definite information. Wunderlich tells us: "That if in a youth or individual of middle age, who was previously well, an illness has continued from five tc ten days, and we find evening temperatures of $103.4^{\circ}$ tc $105^{\circ} \mathbf{F}^{\mathrm{y}}$, or a little over, alternating with morning tem. peratures of $1.4^{\circ}$ to $2.6^{\circ}$ lower, and without any other dis. order showing itself to explain the elevation, and withou1 the patient previously being subject to gross neglect, ther we are justified in positively diagnosing the disease as typhoid fever." There is at the present time in the bospita a girl in whose case the application of this law materially helped us to arrive at a correct diagnosis; from the ninth to the twenty-first days of the disease, as you see from the chart, her evening temperatures mostly reached $103^{\circ}$ to $103.8^{\circ} \mathrm{F}$., with some morning temperatures $1^{\circ}$, and some $2^{\circ}$ lower. This, excepting small successive crops of rose spots, was the only distinct evidence of the existence of the disease; the other symptoms - the condition of the tongue, the character of the evacuations, \&c.-not being at all characteristic. The normal temperature in this case was not reached until the thirty-fifth day.......

To Professor Wunderlich's work on temperature I am much indebted for the information it affords. I last year in my clinical lectures gave you copious extracts from it on febrile diseases in general, on pneumonia, ague, \&c. It is soon to appear in an English form, translated for the Sydenham Society, ${ }^{*}$ and I recommend it to your careful study from the great importance and extreme interest of the subject.

\section{THE NUTRITIVE VALUE OF AUSTRALTAN PRESERVED MEAT.}

Bx S. W. D. WILLIAMS, M.D.,

MEDICAR SUPERINTENDENT OF THB SUSSEX LUNATYC $\triangle$ STIUTM.

Noxwithstanding the fact that Australian preserved meat is being used very extensively in many of our public institutions, there is still a great prejudice against it existing in the minds of many. It would, however, be a great boon to the lower classes if it could be proved to them that preserved meat as nutritious as fresh meat can be put within their reach at as reasonable a price as fourpence-halfpenny or fivepence a pound. Some experiments I have made with a view to roughly testing the nutritive power of the Australian preserved meat as compared with fresh meat before introducing it into our dietary, may be deemed worthy of publication in The LaNcet.

The chronic patients of this asylum, who are in good health and not under special medical treatment, have, inter alia, males twenty-two and females twenty-four ounces of fresh unconked meat during each week, exclusive of the soup. I took twenty of these patients, ten males and ten females, and for one month gave them a similar quantity of Australian preserved mutton instead of the fresh meat, taking care that the other ingredients of the dietary should be exactly as usual. I weighed these patients carefully at the commencement of the month, at the expiration of a fortnight, and at the end of the month, and the following was the result :-

\begin{tabular}{|c|c|c|c|c|c|c|c|c|c|c|c|}
\hline Name. & & & e. 2 nd. & & $\begin{array}{l}\text { Dec. } \\
\text { st. }\end{array}$ & $\begin{array}{c}16 \text { th. } \\
\text { lb. }\end{array}$ & & & c. 30 th & & \\
\hline S. J. C. & $\ldots$ & 9 & $0 \frac{1}{2}$ & $\ldots$ & 9 & 6 & ... & 9 & $5 \frac{1}{2}$ & $\ldots$ & +5 \\
\hline T. R. & $\ldots$ & 9 & 4 & $\ldots$ & 9 & $7 \frac{1}{3}$ & $\ldots$ & 9 & 8 & $\ldots$ & \\
\hline B. S. & $\ldots$ & 7 & $11 \frac{1}{2}$ & $\ldots$ & 8 & 0 & ... & 7 & $11 \frac{1}{2}$ & $\ldots$ & \\
\hline S. G. & $\ldots$ & 10 & 2 & $\ldots$ & 10 & $3 \frac{1}{2}$ & $\ldots$ & 10 & 1 & $\ldots$ & -1 \\
\hline L. R. & $\ldots$ & 9 & 1 & $\ldots$ & 9 & $1 \frac{1}{2}$ & ... & 9 & $1 \frac{1}{2}$ & $\ldots$ & $+0 \frac{1}{2}$ \\
\hline . $\mathrm{P}$. & $\ldots$ & 8 & 3 & $\ldots$ & 8 & 3 & $\ldots$ & 8 & $3 \frac{1}{2}$ & $\cdots$ & $+0 \frac{3}{2}$ \\
\hline A. S. & & 8 & 1 & $\ldots$ & 8 & $0 \frac{1}{9}$ & $\ldots$ & 8 & 0 & $\ldots$ & -1 \\
\hline M. A. E. & i... & 7 & 0 & $\ldots$ & 7 & $0 \frac{1}{2}$ & $\ldots$ & 7 & 0 & $\ldots$ & \\
\hline $\mathrm{H}$. & $\ldots$ & 10 & 10 & $\ldots$ & 10 & $11 \frac{1}{2}$ & $\ldots$ & 10 & $11 \frac{1}{2}$ & $\ldots$ & $+1 \frac{1}{2}$ \\
\hline L. G. & $\ldots$ & 9 & $12 \frac{1}{2}$ & $\ldots$ & 9 & $11 \frac{1}{2}$ & $\ldots$ & 9 & $10^{-}$ & $\ldots$ & $-2 \frac{\bar{l}}{2}$ \\
\hline G. & $\ldots$ & 11 & $3 \frac{1}{2}$ & $\ldots$ & 11 & 2 & $\ldots$ & 11 & $3 \frac{1}{2}$ & $\ldots$ & \\
\hline F. & $\cdots$ & 8 & 8 & $\ldots$ & 8 & 8 & $\ldots$ & 8 & 12 & $\ldots$ & +4 \\
\hline P. & $\ldots$ & 9 & 2 & $\ldots$ & 9 & $5 \frac{1}{2}$ & $\ldots$ & 9 & 3 & $\ldots$ & +1 \\
\hline T. & $\ldots$ & 10 & 1 & $\ldots$ & 10 & 1 & $\ldots$ & 9 & $13 \frac{1}{7}$ & $\ldots$ & -13 \\
\hline C. & $\ldots$ & 9 & $10 \frac{3}{4}$ & $\ldots$ & 10 & 0 & $\ldots$ & 9 & $12 \frac{1}{2}$ & $\ldots$ & $+1 \frac{3}{4}$ \\
\hline M. & ... & 9 & $5 \frac{1}{2}$ & $\ldots$ & 9 & 8 & $\ldots$ & 9 & 5 & $\ldots$ & $-0 \frac{1}{2}$ \\
\hline G. & $\cdots$ & 9 & $12 \frac{1}{2}$ & $\ldots$ & 9 & 10 & $\ldots$ & 9 & $13 \frac{1}{4}$ & $\ldots$ & $+0 \frac{3}{7}$ \\
\hline T. T. & $\ldots$ & 10 & 1 & $\ldots$ & 10 & 0 & $\ldots$ & 10 & $0 \frac{1}{2}$ & $\ldots$ & $-0 \frac{\mathrm{l}}{2}$ \\
\hline A. F. & $\ldots$ & 9 & $11 \frac{1}{t}$ & $\ldots$ & 9 & 11 & $\ldots$ & 9 & 12 & $\ldots$ & $+0 \frac{3}{4}$ \\
\hline . B. & $\cdots$ & 12 & 0 & $\ldots$ & 12 & 1 & $\ldots$ & 11 & 10 & $\ldots$ & -4 \\
\hline
\end{tabular}


From this, it will be seen that thirteen out of the twenty either increased slightly in weight or remained stationary, and that of the others only one lost anything worth speaking of-viz., 4 1b., and this must have been a purely adventitious circumstance. Moreover, there was no symptom in any of them, either of a physical or mental nature, to lead to the supposition that they suffered from the change of diet.

I think, therefore, we may fairly presume that the Australian preserved meat is, weight for weight, equal to uncooked fresh meat as a dietetic agent. There is, however, the cost of the Australian meat to be accurately estimated before an opinion can be given unreservedly in its favour. And this point, unfortunately, does not come out so well as I had hoped. This is due to two reasons-(1) Owing to increased demand, the price has gone up fully $1 \frac{3}{4} d$. since I commenced to use the meat; and (2) the contents of the tins do not weigh out to the quantities stated. Thus, during the thirty-two days the twenty male and female patients were on the Australian mutton $133 \frac{3}{7} \mathrm{lb}$. were consumed. This quantity cost us $\$ 317 \mathrm{~s}$. 8d. The cost of an equal quantity of the fresh beef supplied from the Asylum farm (on which we slaughter all the meat for the establishment) was $2411 s$. $11 \frac{1}{4} d$. Therefore, the advantage in favour of the Australian meat was only a saving of $14 s .3 \frac{1}{4} d$. or a little over $1 \frac{1}{4} d$. per $1 \mathrm{~b} . ;$ in other words, the Australian mutton cost us about $7 d$. a pound; the fresh beef $8 \frac{1}{4} d$.

Hayward's-heath, January, 1872.

\section{A NEW FORM OF DROP-BOTTLE FOR CHLOROFORM, ETC.}

BY J. D A V IES THOMAS, M.D. LoND., F.R.C.S., RESIDENT MEDICAI OFFICER AT UNIVTRSITY COLLEGE HOSPITAL.

ONE of the inconveniences experienced in the administration of chloroform on lint, \&c., is the difficulty of supplying speedily the lint with fresh chloroform from time to time. When an ordinary stoppered bottle is used, a considerable time is occupied in removing and replacing the stopper; and this generally requires the use of two hands. Moreover, the quantity poured out is extremely uncertain. In order to lessen these inconveniences, Messrs. Mayer and Meltzer, of Great Portlandstreet, have constructed for me the bottle represented in the accompanying woodcut. It is a two-ounce graduated bottle, surmounted by a metal cap (A B C), the upper portion of which can be unscrewed from the lower, in order to fill the bottle with the anæsthetic. The upper part contains in its interior the stopper, which is ordinarily kept tight by a spring, but by pressing with the finger on the disc $A$, and inclining the bottle with the spout

(B) downwards, the chloroform will escape

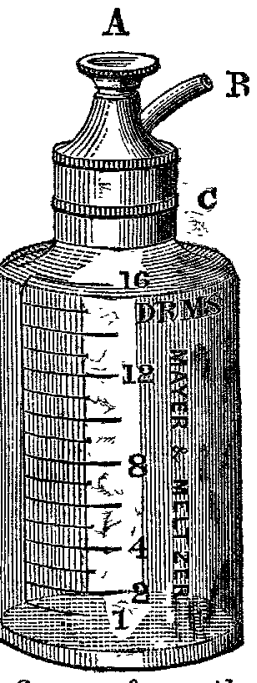

in a uniform stream. By withdrawing the finger from the disc, the flow is at once arrested. As the stream is uniform in size, a short experience will enable the administrator to regulate tolerably exactly the amount of chloroform poured out; and as there is no risk of spilling the chloroform over the patient's face, it is practicable to continue the supply on the lint without removing it from the mouth.

February, 1872

Chesterfield and North Derbyshire Hospital. -Nearly $\$ 3000$ has been promised for the improvement and enlargement of this institution, and it is expected that $\$ 1500$ in addition will be raised by the voluntary offerings of the working men of the towns and district. The plans have been most carefully prepared by an experienced architect, and, when completed, the hospital, in a sanitary and hygienic point of view, will be all that could be desired. The president, the Duke of Devonshire, gives a donation of $\$ 500$.

\section{gy aflitror}

\section{H. O S I T A L PRACT I E}

\section{BRITISH AND FOREIGN.}

Nulla autem est alia pro certo noscendi via, nisi quamplurimas et morborum et dissectionum historias, tum aliorum, tum pronrias sollectas habere, et inter se comparare.-Morgagni De Sed. et Caus. Morb., lib. iv. Procmium

\section{ST. GEORGE'S HOSPITAL.}

CASE OF YELLOW ATROPHY OF THE LIVER.

(Under the care of Dr. WadHanr.)

A. G-, a Swede, twenty-eight years of age, was ad. mitted October 14th with the following history:-He had always been healthy until the previous summer, during the whole of which he had suffered from pain in the epigastrium, with occasional vomiting after food. Three weeks ago his urine became very dark-coloured, and the whole of his body gradually jaundiced. Since that time the pain in his epigastrium had increased in severity, and vomiting had occurred after every meal; he had slept much and heavily, and had suffered from great and constant depression of spirits.

On admission he was very jaundiced. He had tenderness, when examined, over the hepatic region, and the liver on percussion appeared to be smaller than usual. He had pain there, occurring in paroxysms; his pulse was 60 and full; the mucous coat of his tongue peeling off; his urine was loaded with the colouring-matter of the bile, and his motions were solid and clay-coloured.

In this condition, without any vomiting, but with very constipated bowels and great disinclination for food, he remained until the 20th. He then appeared weaker, very confused in his mind, with a heavy look about the eyes, and vomited three times during the day. From this time until the 29 th he was very restless, and frequently vomited a dark-yellow fluid, which stained everything upon which it fell a bright-yellow colour. His bowels remained confined; but the motions when passed, and the urine, retained the same characters as on admission. On the 29th he was much lowered, seemed scarcely to understand what was said to him, was with difficulty kept in bed, and con. stantly vomited yellow fluid. From this time he lay in bed apparently quite insensible, and making a continued moaning noise. He vomited occasionally, and had frequent convulsive twitchings of the left side, which, when not convulsed, appeared as if paralysed. In this condition he remained until his death, which took place at 6 A.Mr. on the 2nd of November.

The post-mortem appearances, as described by Dr. Whipham, the curator, were as follows:-The dura mater was bile-stained, and there was excessively bile-stained fluid in the ventricles. The septum was softened, but the brain was otherwise healthy. The lungs were natural, with the exception of some vascularity of the bronchial mucous membrane, and a little bloody mucus in the bronchi. The endocardium was bile-stained, but the structure and valves of the heart were natural. The spleen weighed nine ounces, and the Malpighian bodies were large and prominent. The kidneys were flabby, partly decomposed, but their surfaces smooth. The gall-bladder contained a little thin, greenish mucus, and the ductus choledochus was open. The liver weighed thirty-two ounces, was flabby, but not especially soft or friable. On both upper and lower surfaces circumscribed patches, of yellow colour and variable size, were observed, which were more numerous and more extensive on the right lobe. On making a section through the liver substance, these appearances were still more marked. Their colour in the central parts of the organ was bright ochrey, which contrasted strongly with the unaffected portions of the hepatic tissue; moreover, the somewhat red and congested state of the unaffected parts rendered this contrast still more conspicuous. The internal parts of the left lobe were far less diseased than any other portion of the organ. The vessels and ducts were in all respects normal.

Microscopic examination was made of portions of both 